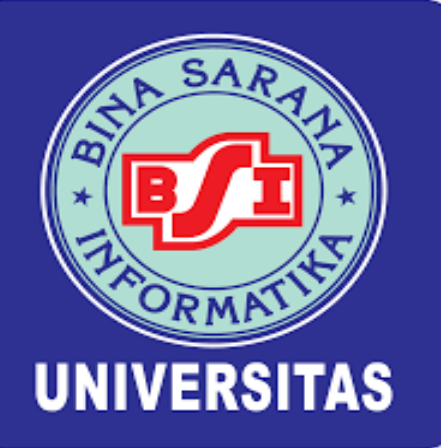

\title{
UKURAN GEJALA PUSAT DATA DIKELOMPOKKAN UNTUK MENGHITUNG NILAI AKHIR STASTISKA KEBUMIAN 2019/2020 (STUDI KASUS) : UNIVERSITAS LAMPUNG KELAS A
}




\title{
Oleh Kelompok 9
}

\author{
Frans gernato -17190311 \\ Saif Amannuloh -17190375 \\ Fitria Nur Salsabila -17190848 \\ Sephia Asyhakaila -17190237
}

\section{Kelas 17.3B.01 \\ Semester 3}

PROGRAM STUDI TEKNOLOGI INFORMASI

FAKULTAS TEKNOLOGI INFORMASI

UNIVERSITAS BINA SARANA INFOMATIKA

$2020 / 2021$ 


\section{PEMBAHASAN}

\section{Pengertian Ukuran Gejala Pusat}

"Ukuran gejala pusat merupakan suatu usaha yang ditujukan untuk mengukur besarnya nilai rata-rata dari distribusi data yang telah diperoleh dalam suatu penelitian."

Beberapa syarat agar suatu nilai dapat dikatakan sebagai nilai sentral, yaitu:

- Nilai sentral harus dapat mewakili rangkaian data

- Perhitungannya harus didasarkan pada seluruh data

- Perhitungannya harus mudah

- Dalam suatu rangkaian data hanya ada 1 nilai sentral 


\section{Pengertian Data Dikelompokan}

"Data yang dikelompokkan adalah data yang sudah disusun ke dalam sebuah distribusi frekuensi sehingga data tersebut mempunyai interval kelas yang jelas dan mempunyai titik tengah kelas." 


\section{Macam-Macam Ukuran Gejala Pusat}

$\square$ Rata-Rata Hitung (mean)

Nilai rata - rata dari suatu kelompok data yaitu jumlah nilai data dibagi dengan banyaknya data.

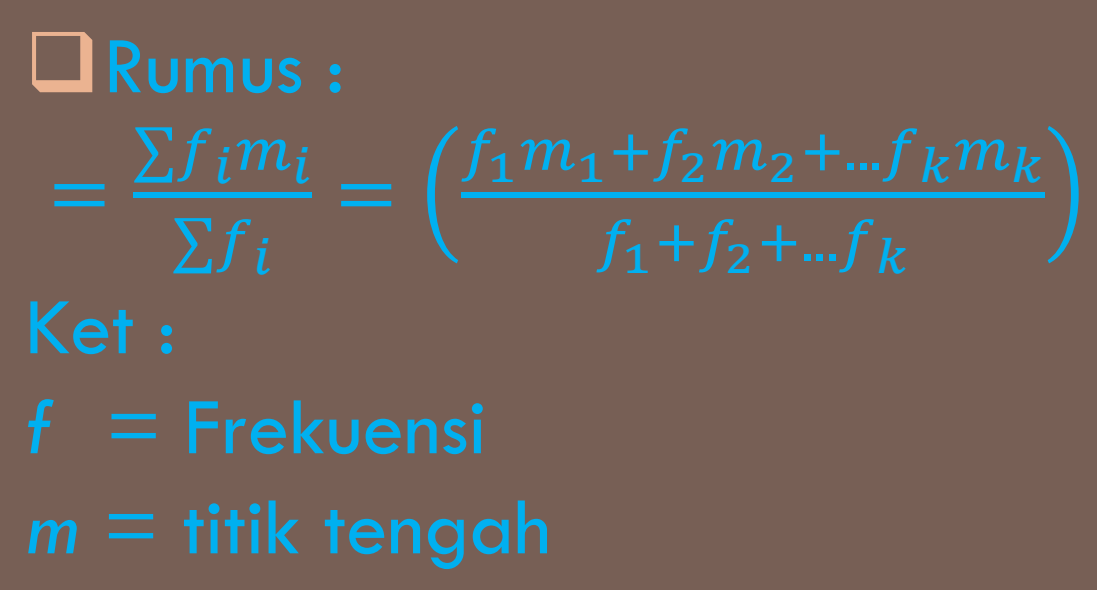




\section{$\square$ Median}

Median merupakan sebuah nilai data yang berada di tengah-tengah dari rangkaian data yang telah tersusun secara teratur.

$\square$ Rumus: $M e d=L_{m}+\left(\frac{\frac{N}{2}-\Sigma f}{f_{m}}\right) \cdot c$

\section{Keterangan :}

\section{Med $=$ median data dikelompok}

$\mathrm{Lm}=$ tepi bawah kelas median

$\mathrm{N}=$ Jumlah frekuensi

$\Sigma f=$ frekuansi kelas median

$c=$ interval kelas media 


\section{$\square$ Modus}

Modus merupakan nilai data yang memiliki frekuensi terbesar atau nilai data yang sering muncul

$\square$ Rumus : $\operatorname{Mod}=L_{m o}+\left(\frac{d_{1}}{d_{1}+d_{2}}\right) \cdot c$

Keterangan :

Mo : modus daita kelompok

$L_{m o}$ : tepi bawah kelas modus

d1 : frekuensi kelas modus dikurangi ,frekuensi kelas sebelumnya

d2 : frekuenso kelas modus dikurangn frekuensi kelas sesudahnya 


\section{$\square$ Kuartil}

Kuartil adalah suatu rumus yang membagi suatu data menjadi kepada empat yang sama banyak. Kemudian dari setiap data yang terbagi sama banyak tersebut dibatasi oleh sebuah nilai.

$$
Q_{t}=T b+p\left(\frac{i \cdot n}{4}-F\right)
$$

\section{Keterangan :}

Qi adalah kuartil ke-i

Tb adalah tepi bawah kelas kuartil

$\mathrm{p}$ adalah panjang kelas

n adalah banyak data

$f$ adalah frekuensi kelas kuartil 


\section{$\square$ Desil}

Desil adalah suatu rangkaian data yang membagi seuatu distribusi menjadi 10 bagian yang sama besar

$$
D_{i}=T b+p\left(\frac{i . n}{10}-F\right)
$$

\section{Keterangan :}

\section{D1 adalah desil ke i}

TB adalah tepi bawah kelas kuartil

$P$ adalah panjang kelas

$\mathrm{N}$ adalah banyak data

F adalah frekuensi kumulatif sebuah kelas desil

f adalah frekuensi kelas desil 


\section{$\square$ Persentil}

Persentil adalah ukuran letak yang membagi suatu distribusi menjadi 100 bagian yang sama besar.

$$
\square \text { Rumus : Letak } P_{i}=\frac{i(n+1)}{100}
$$

Keterangan:

\section{Pi adalah persentil ke-i}

Tb adalah tepi bawah kelas persentil

$\mathrm{p}$ adalah panjang kelas

n adalah banyak data

F adalah frekuensi kumulatif sebelum kelas persentil

f adalah frekuensi kelas persentil 


\section{TABEL}

\section{Tabel Menghitung Nilai Akhir Statiska Kebumian 2019/2020}

\begin{tabular}{|c|c|c|c|c|c|c|c|c|c|c|c|c|c|c|c|c|c|c|}
\hline$\Delta$ & A & B & C & D & $\mathrm{E}$ & $\mathrm{F}$ & G & $\mathrm{H}$ & 1 & $\mathrm{~J}$ & $\mathrm{~K}$ & L & $\mathrm{M}$ & $\mathrm{N}$ & 0 & $\mathrm{P}$ & Q & $\mathrm{R}$ \\
\hline 1 & \multicolumn{14}{|c|}{ DAFTAR NILAI AKHIR MATA KULIAH STATISTIK KEBUMIAN } & & & & \\
\hline 2 & \multicolumn{14}{|c|}{ SEMESTER GANJIL 2019/2020 } & & & & \\
\hline 3 & Mata Kuliah & \multicolumn{3}{|c|}{ STATISTIK KEBUMIAN } & & & & & & & & & & & & & & \\
\hline 4. & Dosen PJ & \multicolumn{3}{|c|}{ DR. AHMAD ZAENUDIN, S.SI. M.T } & & & & & & & & & & & & & & \\
\hline 5. & Kode MK & \multicolumn{3}{|c|}{ TEG616302 } & & & & & & & & & & & & & & \\
\hline 6 & Nomor MK & \multicolumn{3}{|l|}{4505166386} & & & & & & & & & & & & & & \\
\hline 7 & Kelas & \multicolumn{3}{|l|}{ Kelas Kelas A } & & & & & & & & & & & & & & \\
\hline \multicolumn{19}{|l|}{8} \\
\hline 9 & \multirow{2}{*}{ NO } & \multirow{2}{*}{ NPM } & \multicolumn{2}{|c|}{ KUIS } & \multicolumn{6}{|c|}{ TUGAS } & \multirow{2}{*}{ UTS } & \multirow{2}{*}{ UAS } & Keaktifan & NILAI & \multirow{2}{*}{ BIN } & \multirow{2}{*}{\multicolumn{2}{|c|}{ Column! }} & \\
\hline 10 & & & 1 & 2 & 1 & 2 & 3 & 4 & 5 & 6 & & & /Responsi & AKHIR & & & & \\
\hline 11 & 1 & 1615051047 & 0 & 0 & 0 & 0 & 0 & 0 & 0 & 0 & 0 & 0 & 0.00 & 0,00 & 60 & & Mean & 61,4128 \\
\hline 12 & 2 & 1715051001 & 80 & 85 & 100 & 80 & 100 & 75 & 75 & 90 & 30 & 60 & 100.00 & 65,42 & 65 & & Standard Error & 5,5836128 \\
\hline 13 & 3 & 1715051005 & 80 & 85 & 100 & 80 & 100 & 75 & 75 & 90 & 35 & 65 & 100.00 & 68,17 & 70 & & Median & 70,92 \\
\hline 14 & 4 & 1715051007 & 80 & 85 & 100 & 80 & 100 & 75 & 75 & 90 & 65 & 75 & 100.00 & 78,67 & 75 & & Mode & 0 \\
\hline 15 & 5 & 1715051009 & 80 & 85 & 100 & 80 & 100 & 75 & 75 & 90 & 45 & 80 & 100.00 & 75,17 & 80 & & Standard Deviatio & 27,918064 \\
\hline 16 & 6 & 1715051015 & 80 & 85 & 100 & 80 & 100 & 75 & 75 & 90 & 60 & 70 & 100.00 & 75,92 & 85 & & Sample Variance & 779,4183 \\
\hline 17 & 7 & 1715051017 & 80 & 85 & 100 & 80 & 100 & 75 & 75 & 90 & 35 & 65 & 100.00 & 68,17 & 90 & & Kurtosis & 1,6983672 \\
\hline 18 & 8 & 1715051023 & 80 & 85 & 100 & 80 & 100 & 75 & 75 & 90 & 85 & 80 & 100.00 & 85,17 & & & Skewness & $-1,800514$ \\
\hline 19 & 9 & 1715051025 & 80 & 85 & 100 & 80 & 100 & 75 & 75 & 90 & 75 & 70 & 100.00 & 79,67 & & & Range & 85,17 \\
\hline 20 & 10 & 1715051029 & 80 & 85 & 100 & 80 & 100 & 75 & 75 & 90 & 45 & 65 & 100.00 & 70,67 & & & Minimum & 0 \\
\hline 21 & 11 & 1715051031 & 0 & 0 & 0 & 0 & 0 & 0 & 0 & 0 & 0 & 0 & 0.00 & 0,00 & & & Maximum & 85,17 \\
\hline 22 & 12 & 1715051033 & 80 & 85 & 100 & 80 & 100 & 75 & 75 & 90 & 25 & 60 & 100.00 & 64,17 & & & Sum & 1535,32 \\
\hline 23 & 13 & 1715051035 & 80 & 85 & 100 & 80 & 100 & 75 & 75 & 90 & 60 & 75 & 100.00 & 82,42 & & & Count & 25 \\
\hline 24 & 14 & 1715051037 & 80 & 85 & 100 & 80 & 100 & 75 & 75 & 90 & 80 & 55 & 100.00 & 71,42 & & & & 0 \\
\hline 25 & 15 & 1715051041 & 80 & 85 & 100 & 80 & 100 & 75 & 75 & 90 & 30 & 80 & 100.00 & 71,42 & & & & \\
\hline 26 & 16 & 1715051043 & 80 & 85 & 100 & 80 & 100 & 75 & 75 & 90 & 80 & 75 & 100.00 & 82,42 & & & & \\
\hline
\end{tabular}




\section{Hasil}

\section{Pada excel}

\section{$\square$ Hasil dari nilai akhir mahasiswa:}

$\square$ Mean : 61

$\square$ Median : 70

$\square$ Modus: 0

$\square$ Minimum : 0 


\section{Grafik}

Grafik prediksi Data Nilai Akhir Statistika Kebumian 2019/2020

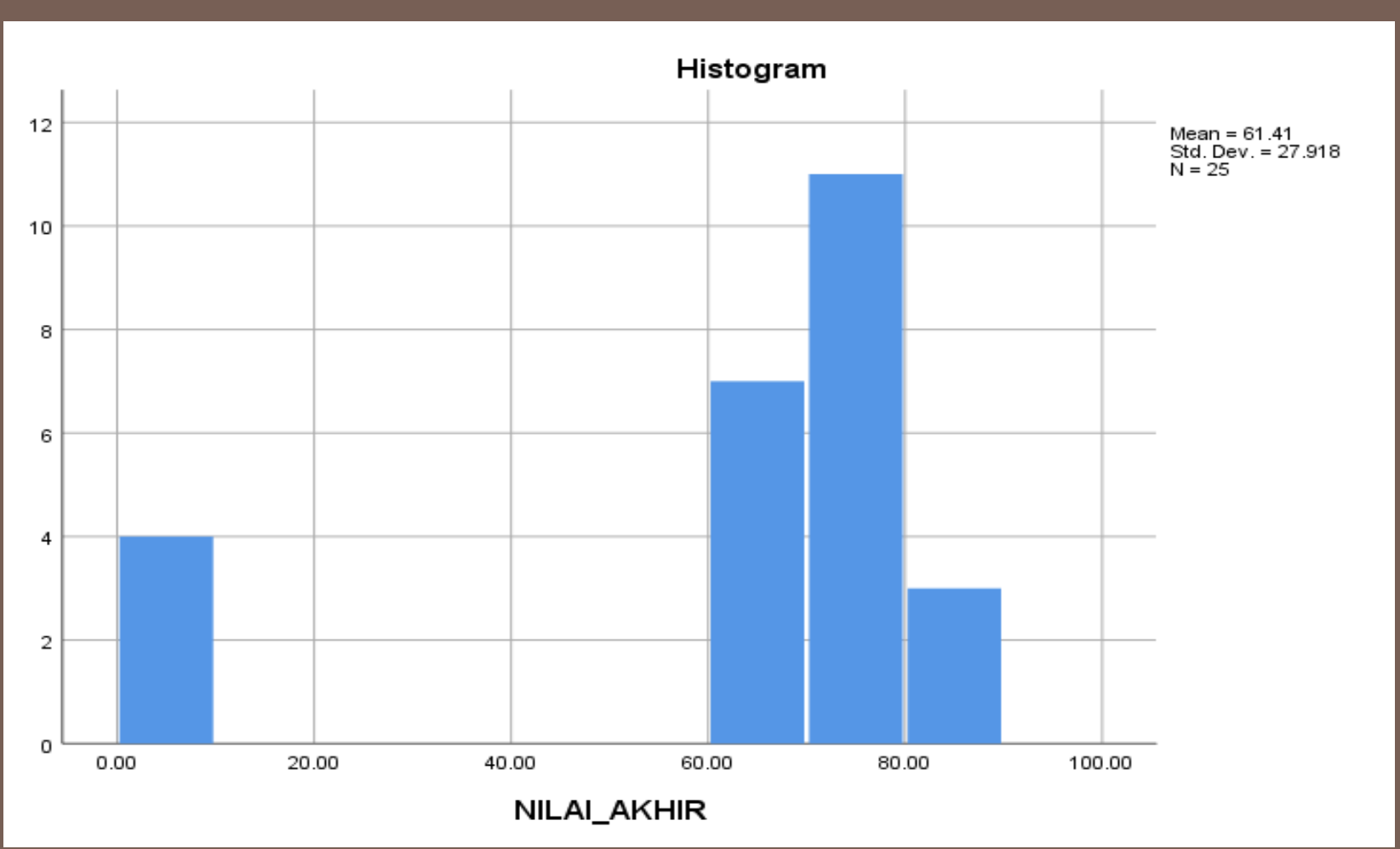

Dari grafik tersebut, nilai rata-rata mahasiswa adalah : 61 , 41 


\section{SPSS}

\section{Perhitungan data nilai akhir statiska kebumian 2019/2020}

\begin{tabular}{|c|c|c|}
\hline \multicolumn{3}{|c|}{ Statistics } \\
\hline \multicolumn{3}{|c|}{ NILAI_AKHIR } \\
\hline \multirow[t]{2}{*}{ N } & Valid & 25 \\
\hline & Missing & 0 \\
\hline Me & & 61.4128 \\
\hline \multicolumn{2}{|c|}{ Std. Error of Mean } & 5.58361 \\
\hline \multicolumn{2}{|c|}{ Median } & 70.9200 \\
\hline \multicolumn{2}{|c|}{ Mode } & .00 \\
\hline \multicolumn{2}{|c|}{ Std. Deviation } & 27.91806 \\
\hline \multicolumn{2}{|c|}{ Variance } & 779.418 \\
\hline \multicolumn{2}{|c|}{ Skewness } & -1.801 \\
\hline \multicolumn{2}{|c|}{ Std. Error of Skewness } & .464 \\
\hline \multicolumn{2}{|c|}{ Kurtosis } & 1.698 \\
\hline \multicolumn{2}{|c|}{ Std. Error of Kurtosis } & .902 \\
\hline \multicolumn{2}{|c|}{ Range } & 85.17 \\
\hline \multicolumn{2}{|c|}{ Minimum } & .00 \\
\hline \multicolumn{2}{|c|}{ Maximum } & 85.17 \\
\hline \multicolumn{2}{|c|}{ Sum } & $1,535.32$ \\
\hline
\end{tabular}

Yang perlu diperhatikan dari data tersebut adalah :

Data Valid : 25

Mising : 0

Mean : 61

Median : 70

Modus : 0

Minimum : 0

Maximum : 85 


\section{Kesimpulan}

Berdasarkan dari hasil penghitungan nilai akhir statiska kebumian 2019/2020 Kelas A adalah :

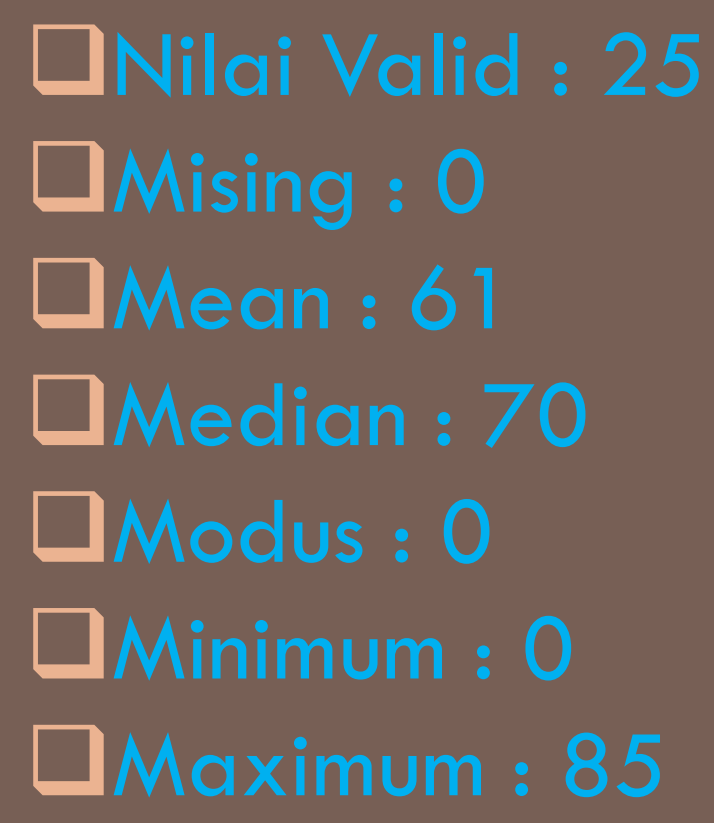


TERIMAKASIH... 